\title{
Patterns of distribution of annelids: taxonomic and spatial inconsistencies between two biogeographic provinces and across multiple spatial scales
}

\author{
V. J. Cole*, M. G. Chapman \\ Centre for Research on Ecological Impacts of Coastal Cities, Marine Ecology Laboratories A11, University of Sydney, \\ New South Wales 2006, Australia
}

\begin{abstract}
Issues of scale and taxonomic resolution are of fundamental importance to studies of biodiversity. To aid in measuring distributions cost-effectively, it has been widely proposed that different levels of taxonomic resolution should be used, depending on the scale of the ecological process or environmental impact being investigated. The effect of taxonomic resolution on patterns of difference in natural spatial variation and abundance of annelids associated with reefs of Sabellaria alveolata was therefore investigated in 2 different biogeographic provinces (Wales and Portugal) over scales of centimetres to 10s of kilometres to identify generality in patterns over different spatial scales and levels of taxonomic resolution. In Wales, there appeared to be some support for the model, with the amounts of small-scale variability increasing with increasing taxonomic resolution. In Portugal there was, however, no relationship between taxonomic resolution and spatial scale. Spatial patterns of annelids grouped at differing taxonomic levels were not consistent between the 2 biogeographic provinces. Any models proposed to explain variation in these patterns must account for differences in patterns among taxa within biogeographic provinces and for the same taxa between biogeographic provinces. This will make such models much more complex than many that have been traditionally proposed to explain spatial variability at different scales.
\end{abstract}

KEY WORDS: Biogenic reef $\cdot$ Biogeographic province $\cdot$ Polychaete $\cdot$ Sabellaria alveolata $\cdot$ Spatial scale $\cdot$ Taxonomic resolution $\cdot$ Variation

\section{INTRODUCTION}

Relationships between patterns of spatial variability of populations or assemblages and the taxonomic resolution to which organisms are identified are of interest for 2 main reasons. First, to improve cost-effectiveness of many sampling programmes, it is important to determine how to partition effort (cost) between increasing number of samples or improving taxonomic resolution in order to identify biologically important patterns (Ellis 1985). Second, spatial variation at different levels of taxonomic resolution is thought to illustrate different ecological processes (Menge \& Olson 1990, Levin 1994). Small-scale local processes, such as competition or predation, are likely to cause variation in populations of individual species at scales of centimetres to 100s of metres (Underwood \& Chapman 1996). Largescale processes, such as historical events, biogeography, or effects of average temperature, may be readily identifiable as changes in taxa grouped into genera or families (Levin 1992) because large amounts of small-scale variability among individual species are generally thought to flatten or average out as data are accumulated over larger scales and longer times (Warwick 1988, Anderson et al. 2005) such that impacts are manifest at higher taxonomic levels (Ferraro \& Cole 1990, Olsgard et al. 1998).

The majority of studies that have investigated issues of scale and taxonomic resolution have approached from the perspective of assessing biodiversity or detecting impacts, for example, pollution (Ellis 1985, Ferraro \& Cole 1990). Such studies have generally 
tested hypotheses about entire assemblages of organisms and have found that the level of taxonomic identification did not affect the ability to detect differences among sites, largely due to the redundancy of much of the data in multivariate analyses (Warwick 1988, Olsgard et al. 1998). Many previous studies that used univariate analyses were also interested in hypotheses about assemblages where multivariate data were converted into univariate diversity indices (e.g. Ferraro \& Cole 1990). Differences detected between assemblages at different spatial scales (Warwick 1988, Olsgard et al. 1998) may have been due to differences in the compositions of different taxa present or to differences in the abundances of individual taxa. Studies that have investigated the question of scale and taxonomic resolution on variation in abundances of individual taxa in undisturbed habitats are, however, less common.

Nested (hierarchical) designs are commonly used to determine the different scales at which organisms are distributed in space (Morrissey et al. 1992). By sampling at a number of hierarchically nested spatial scales, different spatial scales can be compared across species or other taxonomic groups (Underwood \& Petraitis 1993) and quantitative measures of variation for each scale that are independent of all other scales can be obtained (Green \& Hobson 1970). Many studies that have examined relationships between taxonomic resolution and spatial scales of variability have looked at nested scales from metres up to many kilometres in a single set of samples (James et al. 1995, Archambault \& Bourget 1996), although many taxa, marine invertebrates in particular, which have often been the focus of such studies, are notoriously patchy (Underwood \& Chapman 1996). To be able to make generalised predictions, relationships between taxonomic resolution and spatial scales of variability need to be shown to exist in multiple sets of samples.

The majority of studies of spatial variability in marine systems have also been done in heterogeneous habitats, such as soft sediments and rocky shores (Morrisey et al. 1992, Underwood \& Chapman 1996). On rocky shores, small-scale heterogeneity is in the form of pits and crevices, whereas large-scale heterogeneity includes headlands and bays (Archambault \& Bourget 1996). Few such studies (but see Lawrie \& McQuaid 2001, Kelaher et al. 2004) have been done in habitats such as biogenic reefs, which might be more homogeneous over different spatial scales and which might protect the infauna from small-scale variation in environmental conditions (Lintas \& Seed 1994).

Sabellariid reefs are widespread throughout Europe (Dubois et al. 2002), where they may extend for kilometres and cover large areas of shores (Wilson 1971). These are created by encrustations of the tubes of sabelleriid polychaetes, which create complex biogenic habitat for other organisms. Reefs of Sabellaria alveolata in Europe have a diverse assemblage of associated organisms (e.g. Sousa Dias \& Paula 2001, Dubois et al. 2002).

Previous studies have attempted to investigate the role of taxonomic resolution in the ability to detect differences among treatments. These studies have incorporated diverse taxa that have not all been identified to the same level of resolution and 'species' and may include many taxa identified to genus, family or even phylum (e.g. Anderson et al. 2005). This problem can be overcome by testing such ideas with well-described taxa, such as annelids. Annelids often form large components of intertidal marine assemblages; polychaetes, in particular, are often the most abundant taxon in marine habitats (Fauchald \& Jumars 1979). Polychaetes are a diverse component of intertidal benthic assemblages and are often considered to represent the broader assemblage (Olsgard et al. 2003). Furthermore, polychaetes have been illustrated as an appropriate group for use in biogeographical studies (Goblin \& Warwick 2006) because, in contrast to some taxa, their taxonomy is relatively well described, they contain many different trophic levels and life-histories, and they are generally represented in samples by a number of species and families (see Hutchings 1998 for review). Specifically, in terms of this study, polychaetes are an abundant component of the assemblage of Sabellaria in reefs (Porras et al. 1996, Dubois et al. 2002). Previous studies have shown considerable variability in individual species of polychaetes at scales that range from 10s of centimetres (James et al. 1995) to biogeographic provinces (Hernandez et al. 2005), but no previous study examined how spatial variability changes in this taxon with taxonomic resolution or whether similar patterns are found in different provinces.

Based on findings from other habitats (e.g. Warwick 1988, Underwood \& Chapman 1996, Anderson et al. 2005), it was thus predicted that greater small-scale differences and variation would be detected for fine taxonomic groups compared to broad taxonomic groups and that greater large-scale differences and variation would be detected for broad taxonomic groups compared to species or families. It is vital that the results of one study be tested in other places for consistency if generalised models of ecological patterns or processes are to be proposed (Underwood \& Petraitis 1993). It was, therefore, predicted that these patterns would be consistently similar in 2 distinctly different biogeographic provinces. This study uses data from analyses of 5 species, 3 families, 2 classes (polychaetes were compared to oligochaetes) and the phylum Annelida. 


\section{MATERIALS AND METHODS}

Nested sampling of reefs of Sabellaria alveolata Linnaeus was done at the same spatial scales in 2 distinctly different Atlantic provinces separated by over $15^{\circ}$ of latitude. In the cold-temperate boreal province, reefs in Wales were sampled during June 2004. In the Lusitanian province, reefs in Portugal were sampled in July 2004. These provinces were spatially separated by ca. $1600 \mathrm{~km}$. Nested spatial scales were chosen to be relevant to well-known processes that affect the abundance and distribution of marine invertebrates (Barry \& Dayton 1991, Underwood \& Chapman 1996). In each province, in each of 2 regions (separated by 10s of kilometres), 2 shores (separated by kilometres) were sampled (Fig. 1). On each of the randomly chosen shores, 2 sites (separated by 5 to $10 \mathrm{~m}$ ) were sampled. In each site, $n=5$ replicate scrapings of $S$. alveolata (separated by 10 s of centimetres) were taken.
On all shores, the reefs of Sabellaria alveolata were sheets or hummocks that ranged from 10s of centimetres to many metres in size and were 6 to $15 \mathrm{~cm}$ thick. Reefs were on rocky substrata (either large boulders or rocky shore), approximately $1.5 \mathrm{~m}$ above chart datum. Replicates were scrapings of $S$. alveolata within a $10 \mathrm{~cm}$ diameter core to a depth of $10 \mathrm{~cm}$. Samples were not standardised because similar volumes of habitat were sampled among the different cores. Samples were sieved through a $500 \mu \mathrm{m}$ mesh and macrofauna were sorted and identified under a dissecting microscope after refrigeration and preservation in $70 \%$ ethanol. All annelids (not $S$. alveolata) retained on the $500 \mu \mathrm{m}$ mesh were identified to species.

All species of Annelida were grouped as a phylum, or separated into the classes Polychaeta (Portugal 18 species, Wales 20 species) or Oligochaeta, or into families for analyses. Of the 10 families present, 3 were statistically analysed because Syllidae (Portugal 6 species, Wales 3 species), Nereididae (Portugal 2 species, Wales 2 species) and Phyllodocidae (Portugal 2 species, Wales 3 species) were the only families represented by more than 1 species in both provinces. ANOVAs on untransformed data of abundances were done, with each province analysed separately. Estimates of components of variance for each spatial scale within each province were calculated using the mean squares from the ANOVAs. Negative estimates were set to zero and re-calculated following the procedure by Fletcher \& Underwood (2002). Components were converted to percentages of the overall variation to aid comparisons among the different taxa, which had very different abundances. Of the 24 species of polychaetes found, many were too sparse to analyse separately. They were, however, included in all analyses at broader levels of taxonomy.

\section{RESULTS}

It was predicted that there would be larger differences in abundances at small scales for annelids identified to species than when identified at higher taxonomic levels. Small-scale differences (at the site scale of 5 to $10 \mathrm{~m}$ ) were, however, detected across the range of taxonomic groups in Wales and in Portugal (Table 1). Specifically, in

Fig. 1. Portugal and Wales, northeastern Europe, showing the regions (a) Alentejo, (b) Lisbon, (c) Gwynedd and (d) Ceredigion and the shores that were sampled 
Table 1. Summary of spatial scales at which differences in abundances were significant (at $\mathrm{p}<0.05$ )

\begin{tabular}{|lll|}
\hline & Wales & Portugal \\
\hline $\begin{array}{lll}\text { Phylum } \\
\text { Annelida }\end{array}$ & & \\
Class & Shore & Site \\
Polychaeta & & \\
Oligochaeta & Shore & Site \\
Family & Site & Shore \\
Syllidae & & \\
Nereididae & Region & Shore \\
Phyllodocidae & Site & Shore \\
Species & None & Site \\
Syllis gracilis & & \\
Amphiglena mediterranea & Region & Site \\
Eulalia viridis & Shore & Shore \\
Phyllodoce laminosa & None & None \\
Platynereis dumerilii & None & None \\
& Site & Shore \\
\hline
\end{tabular}

Wales, differences between sites were detected at the taxonomic levels of class (Oligochaeta), family (Nereididae) and species (Platynereis dumerilii). In Portugal, differences between sites were detected across all taxonomic groups: Annelida, Polychaeta, Phyllodocidae and Syllis gracilis (Table 1).

Although it was also predicted that there would be greater differences at large scales for annelids grouped at higher taxonomic levels than for individual species, few differences were detected between regions separated by 10 s of kilometres at any taxonomic level. The phylum Annelida differed at scales

Table 2. Percentage variation of abundances of annelids grouped at different taxonomic levels of resolution associated with different spatial scales. Values in bold indicate the greatest source of variation

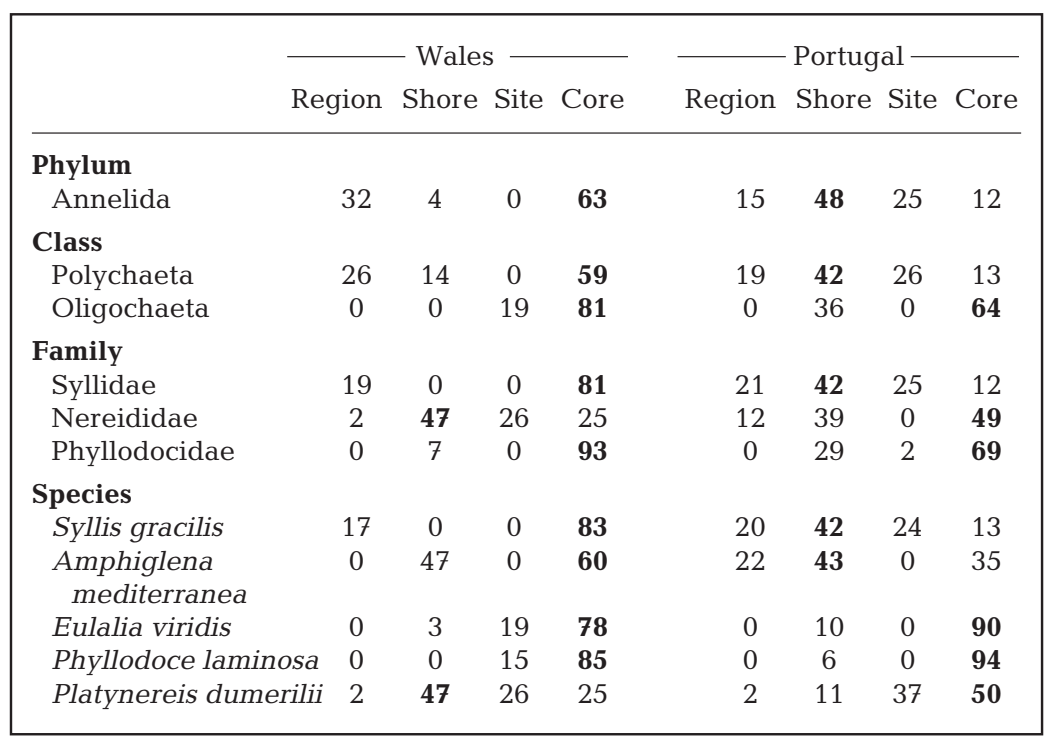

of kilometres or 5 to $10 \mathrm{~m}$ in Wales and Portugal, respectively. Furthermore, the species Syllis gracilis differed between regions in Wales. No large-scale differences were detected at any taxonomic level in Portugal (Table 1).

Variation at the smallest spatial scale (10s of centimetres) among replicate cores was generally large in all taxonomic groups in Wales and Portugal (Table 2), with up to $94 \%$ of the variation at the scale of 10 s of centimetres (Phyllodoce laminosa in Portugal). Variation at other spatial scales was generally small (often zero), with no general patterns of change from places $10 \mathrm{~s}$ of metres to $10 \mathrm{~s}$ of kilometres apart. Overall, patterns of variability were not similar between Wales and Portugal.

\section{DISCUSSION}

In general, contrary to predictions about the scales at which different ecological processes operate, greater small-scale differences were not detected for fine taxonomic groups (species and families) compared to broad taxonomic groups (classes and phylum). Similarly, greater large-scale differences were not found for broad taxonomic groups compared to species or families. Furthermore, the observed spatial patterns and the effects of taxonomic resolution were not consistent between provinces. Thus, in Portugal, either sites or shores (i.e. at scales of 5 to $10 \mathrm{~m}$ or $\mathrm{km}$, respectively) were significant for analysis of the phylum, classes, families, and species. The same taxa showed quite different patterns, however, in Wales. Specifically, differences at scales of 5 to $10 \mathrm{~m}$ were detected there at all levels of taxonomic resolution, and differences at scales of 10 s of kilometres were detected at the level of family and species.

In Wales, there was some support for the hypothesis that the amount of small-scale variability would decrease with decreasing taxonomic resolution, with large amounts of variation at the scale of 10 s of centimetres for species of polychaetes and smaller amounts for broader taxonomic groups. Many explanatory models have been proposed to explain small-scale variability in abundances of organisms, e.g. behavioural responses to habitat or other species, mortality, recruitment (e.g. Levin 1994, Underwood \& Chapman 1996). Predators of polychaetes, such as crabs and blennies (see Hutchings 1998 for review) live in reefs of 
Sabellaria alveolata (Sousa Dias \& Paula 2001, Dubois et al. 2002, V. J. Cole pers. obs.) and thus, the patterns observed here may have been influenced by abundances and very localised foraging ranges of predators.

Small-scale differences in biogenic habitat have also been shown to be a result of the influences of surrounding or epibiotic organisms, e.g. beds of mussels and algae often formed secondary cover on Sabellaria alveolata and occupied the surrounding substratum (Wilson 1971, Dubois et al. 2006, V. J. Cole pers. obs.). This cover was patchy within sites and may have increased small-scale patchiness in the fauna living in the reefs. Disturbances to $S$. alveolata due to waveaction or human intervention (Dubois et al. 2002) and consequent differences in the relative age and stage of succession of $S$. alveolata patches may also create patchiness in the infauna, but one might expect these processes to operate at scales greater than a few centimetres. For example, Porras et al. (1996) found that older reefs of $S$. alveolata supported a greater diversity of associated polychaetes than did new reefs. This might therefore have led to differences in the patterns found at scales of metres to 10 s of kilometres but not necessarily at smaller scales.

Despite there appearing to be a pattern of decreasing amounts of small-scale variability with decreasing taxonomic resolution in Wales, there was no such pattern in Portugal. Furthermore, none of the above models explain why the same taxa show such different patterns in the same type of reef in the 2 biogeographic provinces (Wales and Portugal).

Although most of the variability in Wales was at the scale of 10 s of centimetres, in Portugal there was considerable variation at the kilometre scale at all levels of taxonomic resolution. Variability at large spatial scales of 10s of kilometres was small in Wales and Portugal and did not decrease with increasing taxonomic resolution. Large-scale variation in abundances of marine organisms is generally considered to result from differences in sea-surface temperatures, tides, regional winds, eddies, upwelling, fronts or continental shelfwaves, which may affect large-scale recruitment of organisms with planktonic larvae (Barry \& Dayton 1991). Nevertheless, these models still do not explain why different species (or taxa when grouped as families, polychaetes, oligochaetes, or annelids) should show different patterns of variability at different spatial scales within either province or between provinces.

Lack of support for our models regarding taxonomic resolution and detection of spatial patterns in abundance and amounts of variation was probably due to a variety of complex and interacting processes. Such inconsistencies may have been due to small-scale processes that generally affect species, e.g. predation, dif- fering in intensity at large spatial-scales (Underwood \& Chapman 1996). Within a single species, some polychaetes have been found to have different types of feeding in different places, e.g. predation or suspension-feeding (see Hutchings 1998 for review). Alternatively, large-scale processes that generally affect broad taxonomic groups, e.g. climatic differences (Levin 1992), may have little or no effect on the organisms in biogenic reefs (but see Kelaher \& Castilla 2005).

Although variation at the scale of regions was calculated by sampling 2 different regions within each province (compared to 4 shores, 8 sites and 40 cores), the lack of consistency between regions in Portugal and Wales suggests little support for generalisations at this scale. More data would, however, be needed to test this. Nevertheless, many previous studies that have found a relationship between taxonomic resolution and spatial scale have only tested the prediction once or in one place (e.g. Warwick 1988, Somerfield \& Clarke 1995). If we had only sampled in Wales, we may have believed that the greatest amount of variation for all levels of taxonomic resolution was at the smallest scale of among replicates. The different patterns in Portugal indicate that such general conclusions would have been erroneous. This study emphasises the need, once again, to determine how consistent patterns are before proposing models to explain them (Underwood \& Petraitis 1993)

The present study showed that, contrary to predictions, decreasing taxonomic resolution did not change the spatial scales at which these populations varied in any consistent manner. Although most of the species varied most at the scale of less than $1 \mathrm{~m}$, the same species showed different patterns in the 2 biogeographic provinces and different species showed different patterns in the same places. Different families, classes, and annelids as a whole, varied idiosyncratically at scales ranging from 10 s of metres to 100 s of kilometres, with nearly all of the variability occurring at either the site scale (10s of metres) or the shore scale (10s of kilometres) in Portugal and at a mix of scales from 10s of metres to 100 s of kilometres in Wales.

Although the causes of this inconsistent variability are not known, it does raise a warning about generalising from studies along single environmental gradients in single places. This forms an important basis for understanding the processes that are contributing to spatial patterns and recognising these across space (Levin 1994). By sampling at a hierarchy of nested spatial scales and using a variety of different levels of taxonomic resolution, quantitative patterns of distribution and variability have been obtained for which conceptual models can be proposed. Such models must necessarily account for differences in patterns among taxa within provinces and for the same taxa between 
provinces. This will make such models more complex than many traditionally proposed (e.g. Levin 1994). Because patterns of distribution of organisms depend on complex interactions between large- and smallscale processes (Menge \& Olson 1990), experiments are needed to unravel such complex spatial patterns (Underwood \& Petraitis 1993). Such experiments will need to be done in both provinces if they are to explain the relative importance of processes within and among biogeographic provinces.

As a final note of caution, although the broader taxonomic groups did include many species, the patterns at higher taxonomic levels may have been strongly influenced by the most abundant taxa. For example, the patterns of Polychaeta, Syllidae and Syllis gracilis may have been similar because the majority of polychaetes in Portugal were $S$. gracilis of the family Syllidae. This situation was similar for patterns of Platynereis dumerilii and Nereididae in Wales. These findings are consistent with other studies that have shown that the identification of organisms to higher taxonomic levels displays patterns similar to those identified to species (James et al. 1995, Olsgard et al. 1998). Such findings are generally interpreted as due to common influences of processes, not undue weighting in the broader groups by single species. This is of concern when dealing with univariate or multivariate measures of variability, with many multi-taxa assemblages dominated by large abundances of relatively few of the component taxa. This has implications in terms of what is meant by sampling at different levels of taxonomic resolution, especially if different processes act on a species level, rather than on higher taxonomic levels.

Acknowledgements. Funds were provided by an Australian Postgraduate Award (to V.J.C.) and the Australian Research Council through the Centre for Research on Ecological Impacts of Coastal Cities. We thank G. H. and J. Cole, S. and L. Monteiro, J. Fernandes, L. R. Oliver and C. Hughes for help finding field sites and with field and laboratory work; T. Cruz and J. J. Castro (University of Évora), R. Seed (University of Wales, Bangor) and J. Paula (University of Lisbon) for provision of laboratory space and materials. We are grateful to A. J. Underwood and R. A. Coleman for useful comments on the manuscript.

\section{LITERATURE CITED}

Anderson MJ, Connell SD, Gillanders BM, Diebel CE, Blom WM, Saunders JE, Landers TJ (2005) Relationships between taxonomic resolution and spatial scales of multivariate variation. J Anim Ecol 74:636-646

Archambault P, Bourget E (1996) Scales of coastal heterogeneity and benthic intertidal species richness, diversity and abundance. Mar Ecol Prog Ser 136:111-121

Barry JP, Dayton PK (1991) Physical heterogeneity and the organisation of marine communities In: Kolasa J, Pickett STA (eds) Ecological heterogeneity. Springer-Verlag,
New York, p 270-320

Dubois S, Retière C, Olivier F (2002) Biodiversity associated with Sabellaria alveolata (Polychaeta: Sabellariidae) reefs: effects of human disturbances. J Mar Biol Assoc UK 82: $817-826$

Dubois S, Commito JA, Olivier F, Retière C (2006) Effects of epibionts on Sabellaria alveolata (L) biogenic reefs and their associated fauna in the Bay of Mont Saint-Michel. Estuar Coast Shelf Sci 68:635-646

Ellis D (1985) Taxonomic sufficiency in pollution assessment. Mar Pollut Bull 16:459

Fauchald K, Jumars PA (1979) The diet of worms: a study of polychaete feeding guilds. Oceanogr Mar Biol Annu Rev 17:193-284

Ferraro SP, Cole FA (1990) Taxonomic level and sample size sufficient for assessing pollution impacts on the Southern California Bight macrobenthos. Mar Ecol Prog Ser 67: 251-262

Fletcher DJ, Underwood AJ (2002) How to cope with negative estimates of components of variance in ecological field studies. J Exp Mar Biol Ecol 273:89-95

Gobin JF, Warwick RM (2006) Geographical variation in species diversity: a comparison of marine polychaetes and nematodes. J Exp Mar Biol Ecol 330:234-244

Green RH, Hobson KD (1970) Spatial and temporal structure in a temperate intertidal community, with special emphasis on Gemma gemma (Pelecypoda, Mollusca). Ecology 6: 999-1011

Hernández CE, Moreno RA, Rozbaczylo N (2005) Biogeographical patterns and Rapoport's rule in southeastern Pacific benthic polychaetes of the Chilean coast. Ecography 28:363-373

Hutchings P (1998) Biodiversity and functioning of polychaete in benthic sediments. Biodivers Conserv 7:1133-1145

James RJ, Lincoln Smith MP, Fairweather PG (1995) Sieve mesh size and taxonomic resolution needed to describe natural spatial variation of marine macrofauna. Mar Ecol Prog Ser 118:187-198

Kelaher BP, Castilla JC (2005) Habitat characteristics influence macrofauna communities in coralline turf more than mesoscale coastal upwelling on the coast of Northern Chile. Estuar Coast Shelf Sci 63:155-165

Kelaher BP, Castilla JC, Seed R (2004) Intercontinental test of generality for spatial patterns among diverse molluscan assemblages in coralline algal turf. Mar Ecol Prog Ser 271: 221-231

Lawrie SM, McQuaid CD (2001) Scales of mussel bed complexity: structure, associated biota and recruitment. J Exp Mar Biol Ecol 257:135-161

Levin SA (1992) The problem of pattern and scale in ecology. Ecology 73:1943-1967

Levin SA (1994) Patchiness in marine and terrestrial systems: from individuals to populations. Phil Trans R Soc Lond B 343:99-103

Lintas C, Seed R (1994) Spatial variation in the fauna associated with Mytilus edulis on a wave-exposed rocky shore. J Molluscan Stud 60:165-174

Menge BA, Olson AM (1990) Role of scale and environmental factors in regulation of community structure. Trends Ecol Evol 5:52-57

Morrisey DJ, Howitt L, Underwood AJ, Stark JS (1992) Spatial variation in soft-sediment benthos. Mar Ecol Prog Ser 81: 197-204

Olsgard F, Somerfield PJ, Carr MR (1998) Relationships between taxonomic resolution, macrobenthic community patterns and disturbance. Mar Ecol Prog Ser 172:25-36

Olsgard F, Brattegard T, Holthe T (2003) Polychaetes as surro- 
gates for marine biodiversity: lower taxonomic resolution and indicator groups. Biodivers Conserv 12:1033-49

Porras R, Bataller JV, Murgui E, Torregrosa MT (1996) Trophic structure and community composition of polychaete inhabiting some Sabellaria alveolata (L) reefs along the Valencia Gulf Coast, Western Mediterranean. PSZN I: Mar Ecol 17: 583-602

Somerfield PJ, Clarke KR (1995) Taxonomic levels, in marine community studies, revisited. Mar Ecol Prog Ser 127: $113-119$

Sousa Dias S, Paula J (2001) Associated fauna of Sabellaria alveolata colonies on the central coast of Portugal. J Mar Biol Assoc UK 81:169-170

Underwood AJ, Chapman MG (1996) Scales of spatial patterns

Editorial responsibility: Roger Hughes (Contributing Editor), Swansea, UK of distribution of intertidal invertebrates. Oecologia 107: $212-224$

Underwood AJ, Petraitis PS (1993) Structure of intertidal assemblages in different locations: how can local processes be compared? In: Ricklefs R, Schluter D (eds) Species diversity in ecological communities: historical and geographical perspectives. University of Chicago Press, Chicago, IL, p 38-51

Warwick RM (1988) Analysis of community attributes of the macrobenthos of Frierfjord/Langesundfjord at taxonomic levels higher than species. Mar Ecol Prog Ser 46: $167-170$

Wilson DP (1971) Sabellaria colonies at Duckpool, North Cornwall, 1961-1970. J Mar Biol Assoc UK 51:509-580

Submitted: January 18, 2007; Accepted: May 21, 2007

Proofs received from author(s): September 17, 2007 